\title{
The role of emotion in enabling and conditioning public deliberation outcomes: a sociological investigation
}

\begin{abstract}
Citizen participation in deliberation activities within public health systems is increasingly seen as essential in achieving more patient-centred, equitable and democratic care. However recent studies show patients' lived, affective experience of illness and care remains poorly understood within deliberative fora. In response, this paper argues that emotion is central in mediating deliberation, and in conditioning deliberative outcomes. To understand how this occurs, we use a sociologicallyinformed notion of 'biographical affect' to address links between emotion, and social and political action. Benefits of this approach for healthcare deliberation are illustrated through an in-depth case study of a major citizen participation forum in the UK National Health Service. Our conclusions call for alternative orientations to participation that involve committed engagement with participants' affective experiences.
\end{abstract}

Keywords: citizen participation, public deliberations, health, politics of affect

\section{Introduction}

This paper examines the important yet under-researched role of emotions in mediating public deliberation, with a particular focus on citizen participation in health systems. In recent decades, there has been growing interest in deliberation as a tool for improving democracy in the operation of public services. Deliberation can be defined as the 'giving, weighing, acceptance or rejection of reasons' (Parkinson 2004, in this journal), communicated between people through discourse (Carpini et al. 2004). Citizen participation is a prominent method of deliberation, at both individual (micro) and public (macro) level ${ }^{1}$. Within the healthcare context, micro-level deliberations position patients as 'active citizens' taking responsibility for planning their own

\footnotetext{
${ }^{1}$ Here we use the distinction with reference to the question of citizen/patient participation at the individual and the collective level of decision-making. The standard distinction between micro and macro deliberation is made by Hendricks (2000), who considers the former as occurring within specified and designated groups - which are not necessarily representative of the public and hence democratic - and the latter as public debate in the media and conversations on the ground level: what is termed 'discursive democracy'.
} 
options and choices for treatment (Bovaird 2007, in Eriksson, 2012). Deliberations at the macro level, which constitute the primary focus of this paper, involve putting policy questions to groups of citizens 'who are given information, listen to arguments, debate the issues' (Parkinson, 2004, p. 377) and offer recommendations to public organizations that enact policy. Such groups of citizens can increasingly be found in health policy (Eriksson 2012, in this journal), wherein deliberation is said to 'democratize' health systems and improve quality of health decisions (see Martin 2011; Parkinson 2004).

This proliferation of deliberative practices in health is manifested in a range of government initiatives internationally such as 'user fora' in the UK, 'consumer groups' in Canada, 'participation committees' in Italy, 'community councils' in Portugal and 'health territorial governments' in Spain (for a recent review of the latter three, see Serapioni and Matos, 2015). Yet in spite of such overwhelming adoption of deliberation there have been serious criticisms: several authors argue that an overly rationalistic framework for deliberation tends to exclude and often de-legitimise certain participants and discourses (Barnes 2008; Carr 2007). Furthermore, professionals participating in deliberations often struggle to handle emotional input for instance anger - expressed in meetings and discussions with patient representatives (Renedo et al 2014), or question the authenticity and representativeness of emotional views contributed in scientific debates (Martin 2012). Consequences include disengagement from formal deliberation processes, slipping into tokenistic behaviors of 'ticking boxes' (Petit-Zeman and Locock 2013), and limiting emotional interaction to informal or peripheral organizational spaces. 
In response, we address a relative lack of theoretical and empirical work that qualitatively assesses the impact of emotions on policy deliberations (Manning and Homes 2014) - a gap particularly visible in public administration literature (for notable exceptions see Sullivan 2015; Dickinson and Sullivan 2014) We argue that emotions are important precisely because of their structuring and conditioning effect on deliberative outcomes. Accordingly, we draw on organizational theory representing the recent 'affective turn' within social sciences, to develop a macrolevel, sociological framework that deepens existing understanding of the conditioning function of emotion within healthcare deliberation fora. Specifically, we propose the concept of 'biographical affect' to engage with emotionally-mediated, semi-conscious motivations that have material bearing upon the visible (discursive) level of deliberation. So doing, we draw attention to emotion's equivocal operation in challenging, as well as sustaining, deliberative organizational outcomes. We discuss the implications of these findings for both policy-making and public administration, highlighting the benefits of 'emotionally-literate' processes in mitigating ineffective and tokenistic application of patient participation in health.

Theories and practices of deliberation: Limitations and opportunities for the study of emotion

Public deliberation has been long theorized as a cornerstone of participatory democracy (Barber 1984; Dahl 1989; Dewey 1954 [1927]; Fishkin 1995; Habermas 1996). Deliberation is seen as a forum for the creation of public agreements (Elster 1998), where ideally, 'no force except that of the better argument is exercised' (Habermas 1975, p. 108). Arguments reflect a host of 'political rationalities' (Behagel and Arts (2014, in this journal), which mainly address legitimacy deficits around 
policy making (Montpetit 2008) while doing little to counter power deficits - reducing participation to pre-defined agendas and leaving underlying 'network-like fields of power' unchallenged (Eriksson 2012). Hence critical discussions of deliberative democracy tend to focus on the way rationality excludes or co-opts lay and non-expert perspectives. If emotional experiences are enshrined in such perspectives, what can we discern about their impact on rational reasoning and its outcomes?

Dryzek (2000), the leading figure of the 'deliberative turn' in political science, has argued for a more open notion of deliberation that does not consider rational argument as the sole form of 'authentic deliberation', but rather, allows for 'humour, emotion, storytelling, and gossip'. (ibid., p. 3). Dryzek proposes that excluding emotional responses suppresses and delegitimizes alternative ways of deliberating; 'Still', he highlights, 'emotion can be coercive; which is why in the end it must answer to reason' (ibid.). In fact, deliberative democracy is often seen as a 'corrective device' for avoiding such passion-led coercion (e.g. Marcus 2003). Although these views acknowledge a role for emotion within deliberative practice, it is invariably positioned antagonistically in relation to reason.

More recently, Gottweis (2012) has proposed a re-interpretation of emotions as 'pragmatic acts' and 'communicative performances' that constitute legitimate modes of argumentation. Recent research into patient and public involvement has also begun to revise the emotion/reason dualism, discussing emotion's more complex links with reason in health deliberations (e.g. Barnes 2008; Martin 2012; Renedo et al. 2014). A concern with the structuring role of emotional practice is implied in this stream of work, which suggests that patients' emotional engagement when deliberating a topic 
can also enhance cognitive engagement and therefore contribute to better involvement practices (Davies et al. 2006).

These studies suggest that on the one hand emotional engagements can lead to passionately argued contributions, strong identification with issues, and enhanced cognitive engagement. (Davies et al. 2006). On the other hand the legitimacy conferred by emotive discourse may lead to 'closures of deliberation' that exclude vulnerable voices from the process (Martin 2012), validate morally pre-agreed outcomes (Anderson 2014), or - more worryingly - allow for managerial manipulation of laypeople (Hodge 2005). But how can we trace the impact of such emotional underpinnings of deliberation on organizational outcomes? The next section offers a sociologically informed conceptual lens for better understanding the reciprocal relationship between emotions and unfolding organizational structure, in practice.

\section{Using the concept of biographical affect to unpick emotion's structuring role}

Within organization studies the recent increase of interest in emotion and affect is striking (Elfenbein 2007; Schmidt and Gibson 2010). Organizational emotion literature has its roots in cognitive rationalism, (where emotions 'disrupt reason'), but has since addressed links between emotions and organizational productivity, (e.g. Maslow 1970, Herzberg 1966), as well as 'cognitive', non-emotional concepts such as negotiation, conflict management, and game theory. More recently seminal studies indlude Hochshild's (1983) work on emotional labour, Van Maanen and Kunda's 
(1989) focus on organizational culture and emotions, and Goleman's (1998) study of emotional intelligence.

Although it is beyond the scope of this paper to offer a comprehensive review of the wider 'sociology of emotions' literature, this brief overview traces a progressive challenge to a long-standing, rationalist conception of practice, which mirrors the predominantly deliberative worldview that exists within citizen participation in health. We position our own work within this contemporary field, but broaden our focus from 'emotions' to encompass 'affect' ${ }^{2}$. Although the concepts of emotion and affect are often used loosely and interchangeably, we make a distinction here between the two: affect is evoked by lived and pre-reflexive bodily experiences as they 'pass from person to person'; it often remains unspoken and affects people before its resulting 'intensities' are named and categorized as emotions (Fotaki et al. 2014). Although deeply rooted in affective, social experiences from the past, emotions are evoked in the present, are more subjective, and mediate peoples' behavior and agency. In this view, affect has a conditioning role, via emotions, on the way in which deliberation unfolds, with resulting implications for organizational outcomes.

Developing the above, we are concerned with problematizing links between the immanence of latent, affective experience that people bring to, and generate within, social encounters, and resulting social outcomes. Echoing McLuhan's dictum that we see the present through a rear-view mirror (1967, p. 75), this view explores the

\footnotetext{
2 This is transition of focus is reflected in the 'affective turn' within the social sciences, addressing the artificial separation of emotion and reason, within sociology (e.g. Hochschild 2011; Fortier 1999; Archer, 2000), organization studies (e.g. Fineman, 1993), human geography (e.g. Thien, 2005, Whitehead et al., 2005), and neuroscience - where, for example, Damasio (1994) provides clinical evidence that the rational is built out of the affective, and that consciousness itself is a form of feeling (see also Marcus 2002). Within philosophy, Nussbaum (2013) has argued that emotion functions as a deep source of human awareness that informs critical judgment, and as such constitutes the basis for thoughts and actions that move us forward.
} 
operation of affect in structuring perceptions of, and reactions to, the present in what Thrift has referred to as "a constantly moving preconscious frontier" (2004, p. 67). Thrift emphasizes the 'political' nature of this affective expectation of the world - in other words, how our embodied stance towards (and subsequent agency within) unfolding reality is conditioned by our cumulative interaction with social structures which can thus be said to be 'immanent' within the unfolding present. Our view of affect as 'immanent structure' reflects how consideration of any instant is already a memory by the time we are able to give it our conscious attention, but in turn our memory of this instant colours the way we are able to experience it in the present; a form of historically inflected consciousness (Gadamer 1974).

We seek to explore how these affective, and physical, structures respectively of unfolding practice are mediated by the intensities of emotion. To do so we employ a sociologically-oriented concept of 'biographical affect' (Thompson 2012). Thompson explains how this concept encourages attention to the way in which a semi-conscious, viscerally-experienced sense of self, developed and sustained over historical time, enables (and motivates) a person to position herself relationally against unfolding social reality (2012, p. 195). We find the invisible, but structuring operation of biographical affect to be a useful lens for conceptualizing and apprehending a more affectively-historical, yet emotionally-mediated, understanding of unfolding social reality; however, Thompson (2012) did not develop this notion further and it has yet to be applied to empirical data.

Our own use of biographical affect is as a sensitizing concept for explicit consideration of historically-derived affective positioning arising from previous life- 
experiences, that participants bring with them to, and enact within, deliberative fora. The concept focuses on immanent temporal structures in the form of past affective experiences, such as, in this instance, illness, disability, caring and being cared for, as well as future orientations towards states of recovery, rehabilitation, wellbeing and improvement of health systems at large, mediated via unfolding emotional responses to social encounters in the present.

\section{Case study: context and methods}

The UK context resonates well with our focus on emotions in deliberation, as UK health policy discourse is amongst the most assertive about the importance of emotional experience throughout the commissioning and evaluation of health services and health research (e.g. DH 2010). Our case study discusses deliberative activities over a period of two years, between 2009 and 2011, within the largest clinical research network in the UK, a partnership organization that brings together 22 third sector funders and government departments to coordinate cancer research nationally. We focus specifically on the role of the patient involvement forum within the organization, which has a membership of 60-65 persons including cancer survivors and cancer carers. The forum was established in 2001 with two aims: a) to enable patient representation across 21 research groups, where service users attend meetings with professional researchers and discuss the development of new research, including strategic priorities, as well as the design, implementation and evaluation of studies, and b) to provide a space in the organization for service users to meet, sharing experiences gained from their involvement in deliberating research, and co-ordinating their activities in the organization. 
In this paper we draw on data from 28 45-120 minute interviews with participants in the forum. Interviews were conducted as part of ethnographic research in the organization, which also included over 100 hours of participant observation. Interviewees were typical of the participants we observed in the ethnographic study, in that almost all were white, educated, and from professional backgrounds. Interviewees comprised cancer survivors (10), long-term carers (4), cancer survivors who had also acted as carers in their family (1), senior clinical researchers that chaired and attended research group meetings with service users (7), managers (3), and administrators/facilitators (3). The majority of patient/carer representatives and managers/administrators were female, whereas the majority of clinical professionals were male, reflecting the overall gender composition within the organization. Interviews with patient and carer representatives were open, and addressed their experiences of cancer - their 'life stories' - as well as their views and feelings about the forum and day-to-day interactions with professionals. Interviews with professionals allowed us to understand the 'clinical side' of the story, in particular how their thoughts and feelings resonated with the patients' own experiences of the deliberation process. Professionals' accounts also added insight into the context and the operationalization of 'patient involvement' in the research groups, and illuminated expectations and assessments of deliberation within the organization.

An abductive approach to data analysis was adopted (Alvesson and Skoldberg 2000), starting from the empirical material, and applying biographical affect as a lens to reveal links with the two main categories of deliberative outcomes that we observed: 'supporting deliberation', by way of aiding the prescribed organizational agenda, and 
'deviating from deliberation', through undermining or interrupting this agenda. We then conducted open coding (Strauss 1987) of the interview data iteratively, to discern themes within each of the two categories. We focused on interviewees' rich descriptions of motivations for becoming involved in the forum, their moods, assessment of interactions, and trajectories through which they made choices during deliberations (e.g. Renedo and Marston 2015). Some of our codes included for example 'feeling frustrated/angry', 'developing social ties', 'invoking illness memories', 'seeking consensus'. Codes usually described participants' selfpositioning within, and negotiation of, the spaces within deliberation. Our analysis sought links between interviewees' emotional interventions in the deliberation process and their perception of the consequences of such interventions. Two tentative conceptual themes emerged around 'modes' of affective structuring of the deliberation outcomes: a proactive mode, where participants are more conscious of the impact of their emotional commitments on making sense and acting in the present, and a reactive mode, where biographical affect seemed to elicit more unexpected emotional responses in the present.

\section{Findings: affective structuring of organizational outcomes}

Our findings below illustrate: i) 'what' affective structuring in the organization consisted of, by tracing its impact on specific organizational outcomes, in terms of 'supporting', and 'deviating from' deliberation; and ii) 'how' affective structuring operated in the day-to-day life of the organization (either 'pro-actively' or 'reactively'), leading to those specific outcomes. We then discuss the organizational responses to this affective structuring, which we place in two broad categories: 
'rational containment', where the organization seeks to control emotion and delineate boundaries within which it is allowed to surface, and 'irrational challenge', where emotion's generative role is recognised and endorsed. Lastly, we consider the resulting tensions for participants in healthcare deliberations. Table 1 below summarises these findings:

Insert Table 1 About Here

Reflecting our sociological focus on affect and organizational outcomes, and following our concept of 'biographical affect', we engaged with interviewees' own narratives looking for biographical depth. For instance, many of the patient and carer representatives spoke at length about their past experiences of dealing with cancer in their own lives or those of their loved ones - experiences that were central to their choice to become 'involved citizens'. The passage below captures one such affective experience; it is a recollection of Maria, a carer representative who had cared for her dying husband throughout the final stages of prostate cancer, and we cite it here because it offers a good description of our notion of affect as a complex, corporeal state of being, rather than a psychologized emotion:

Out of hours care and that kind of thing, which I think people are waking up to. We were fortunate, he did have a place in the hospice, but even then it wasn't easy for him at all. Because he was on morphine, and morphine brings problems like diarrhoea and vomiting, or constipation sorry and vomiting... and then it's difficult, because I think people did their best, but I began to wonder sometimes if they could trust, having to ring the out of hours doctor every time, and then wait for someone to come, and then someone to say that we've got to get the stuff, the 
anti emetics and the rest of it, why couldn't they just leave some? Well eventually they did, we were trusted I suppose, but that didn't happen overnight and it caused a considerable amount of distress because I would think I wish I could ring the doctor, and my husband would say I don't want you to. So I did these things, I did them with the best will in the world, but I can't say that it was an easy ride...

[Q1: Maria; carer representative, interview, p. 15] [Maria 1]

\section{Supporting deliberation}

The first theme that emerged in our analysis was an affective structuring of outcomes through active exchanges, made in the present, that activated historically latent emotional pre-dispositions, generating emotional experiences with the effect of supporting 'rational' deliberation practice in citizen participation. Hence, as a result of her specific emotional experience described above, Maria enacted a form of involvement when she took the decision to join the organization:

And I thought oh well, I think by now I know a fair amount, maybe I could help. . . but I decided that it was probably better for my own personal wellbeing to use my experience of research and experience I got of palliative care and all the rest of it, in a more general setting rather than prostate cancer, because it might have been a bit upsetting to find what was coming on stream that hadn't been available . . . [I] joined [the] palliative care subgroup because obviously with the experience of the last six/seven months of life with my husband I had a pretty good idea of what could happen in the end of life stage, or what didn't happen as the case may be. 
[Q2: Maria; carer representative, interview, p.14, our emphases] [Maria 2]

Maria's past emotional involvement in caring for her husband shaped her decision to join the organization as a member in the palliative care, rather than prostate, cancerspecific research group - as she did not want to be upset by discussions about specific treatments that would not have been available to her husband. Her corresponding aim during deliberation was to help others facing the experiences that she as a carer and her husband as a cancer patient had suffered. Other patient representatives such as Mike, a throat cancer survivor, reflected on the ways in which another specific type of affect, the experience of loss, imbued their present involvement in the deliberation process with 'some sort of meaning' (quote 3), allowing them to construct some positive self-identifications with their (past) biographical experience and strengthen their will 'to make a difference':

But I think the only thing that runs through, the golden thread for me is... that it helps to make meaning of people's lives. I work in the shop because I lost a loved one. And maybe this helps to make meaning of going through that tragedy. And somebody choose ... and I've never heard that described in, heard people going on research trials, faith, hope, charity. I've heard people saying they want to make a difference. And I don't know, this is in my head. It just seems that the golden thread is that it may be helps to make some sort of meaning. And actually if we then use that thread to tie people up to say well actually for the first time ever that meaning can make a real difference in service delivery. But I don't think we're there yet. 
[Q3: Mike, patient representative, interview, p. 28]

In this case, Mike's engagement in deliberation was a process of meaning-making in the unfolding present, drawing on hopes and faith in a future where they will be able 'to make a real difference in service delivery' (quote 3 ). In so doing, it appeared to complement deliberation aims such as the funding of research leading to longer-term service improvement. In these two examples, affective structuring resulted in supporting deliberations through the operation of a pro-active mode. Maria and Mike are conscious that the way in which they feel about themselves in the unfolding present is conditioned by their past biographical experience: their emotional awareness of these affective structures appears to guide their behavioral response to the organizational environment. Emotion is seen here as an important structuring medium that:

...not only "represents" yourself, it is also intrinsically evaluative. It imparts value. It tells us whether something is "good" or "bad"; and it does that by making things feel good or bad (or somewhere in between). (Solms and Turnbull, 2002, pp. $90-1$, in West 2007, p. 36).

However in our interviews with participants we also observed another mode of affective structuring, where emotions-in-the-present deriving from affective biographical experience appear unexpectedly, rather than as part of a consciouslychanneled narrative, often taking participants by surprise:

But [the clinical Chair] said to me you know when you spoke, it had a tremendous effect. I said really, no idea. He said oh yes, quite a few people looked down and you could see that you were making them think. And I said I can't remember what 
I said. He said well you spoke from the heart. . . I know in my last meeting I made a plea, because by that time of course my husband had died and we had discovered for ourselves how little there was in the way of late stage cancer research. I made a plea for more research into the later stages of metastatic cancer.

[Q4: Maria, carer representative, interview, p.19] [Maria 3]

A striking feature in Maria's description is the lack of immediate realization of the effect of her emotionally-driven and communicated plea on the clinical researchers sitting across the table - and hence on the deliberation process itself. Her affectivelymediated biographical narrative, stretching into the past (caring for her terminally ill husband) and reaching into the future (aim to shift research priorities towards late stage cancer), worked as a structural enhancement on unfolding, present deliberative practice. What the clinical professional cites as 'tremendous effect' (quote 4) is not clear here but one can assume that it had affected other participants in the deliberation process.

\section{Deviating from the deliberation process}

Participants' emotional engagement, and its affective structuring of deliberation, was not always seen to be positively embedded within established involvement practices. Often, an emotionally-loaded intervention might disrupt deliberation, surfacing involvement orientations that appeared in conflict with organizational aims, and mobilizing management controls of emotional behavior within deliberations. 
Proactive and reactive modes of conditioning were both in operation in this 'deviating' type of affective structuring.

In such cases, proactive emotional involvement was cast by some professionals as a deviation from the deliberation process, and relegated to a private realm that should have no place in the formal organization. Rita, a manager responsible for coordinating citizen participation across the research groups, explained how some participants' proactive mode of structuring resulted in deviation from, and challenge to, the deliberative norms of the group:

There's been a couple of really, really stroppy female consumers [we] used to have quite a lot of chats about this and we both quietly had words with her saying, you're not ... and she had a lot to give, she had really good background knowledge, she thought about things. But the way she approached it was completely, a complete turn off. And she clearly came with a lot of emotional feelings about how what had happened to her relative and wanted to promote research in that particular direction. But didn't always handle it properly so people just completely switched off and she was not reappointed to the group. The chair wouldn't agree to reappoint her.

[Q5: Rita; manager, interview, p.13] [Rita]

In this example, it is not simply the emotional charge of patient involvement that is 'displaced' from the formal organization, but devastatingly the patient herself, who becomes an obstacle to the process: a 'complete turn off' (quote 5) for this 
deliberation. Rita's proactive behavior in the present was conditioned by strength of feeling that resulted from her own past biographical experience - and yet in this example, the organizational result of this conscious emotional narrative was seen as conflicting with the aims of the deliberation process.

Other patients recalled emotionally-loaded moments when discussion in some of the long meetings with professional researchers was interrupted by the more reactive emotional responses of those attending. For example, Helen, another cancer survivor who had also cared for her brother, Peter, who had died of cancer, said:

I do remember being at a meeting . . . I remember there was some dialogue going on about something and I can remember getting extremely emotive because we just seemed to be going round and round the table going absolutely nowhere, wittering on about something that wasn't particularly of much use. And as I say, I can remember getting almost in tears over it saying that cancer was a very basic thing; you've really got to look at the person, the emotions. .. . It seemed to get agreement to come back to it but you didn't really know whether they were truly believing it or actually couldn't feel it because they hadn't been there. I mean I've got the way I felt and it is the way I felt. Mine felt as it did because of it and also because of Peter not long dying and somebody else would have a similar sort of thing.

[Q6: Helen; patient representative, interview, p. 30] 
Reading this extract, one is struck by the way in which Helen's visceral experience of caring for her brother, and of his subsequent loss, constitutes an immanent, if invisible, structural constraint upon the discussion, by positioning her to undergo a particular emotional response to the unfolding dialogue. Helen's emotional engagement inflects her perceived role (defined in opposition to expected 'professional' standards of deliberation) and, in disrupting the professionals' discussion, steps beyond the deliberation process itself. In so doing, biographical affect affords an alternative 'framing structure' through which Helen is able to challenge deliberation's relationship with the "reality" of the things under discussion' (Anderson 2014, p. 5).

\section{Organizational responses to affective content and resulting tensions}

Just as both proactive and reactive modes of affective structuring could result in different organizational outcomes, organizations themselves were predisposed in different ways to the emotionally-mediated presence of biographical affective structures: some (mostly professional) respondents argued for sensitive (rational) containment of emotions within healthcare deliberations, and others positively relished the disruption that such non-rational input could cause. Here is what Chris, a Chair of one of the research groups expressing strong support for patient involvement, had to say:

I think to have a user whose experience was very raw and still very highly emotionally charged might be tricky, and indeed we have in one of our groups had 
one of the users present who'd suffered yet another bereavement. And in a sense I think that was helpful for the group, because what we realised was that, here is someone who's in the middle of this experience called grief, right now, that we're trying to research, so ... you don't want too much of that, because the emotion of the moment can hinder discussion.

[Q7: Chris, clinical researcher, interview, p. 9]

Chris described the 'highly emotionally charged' experience in his research group meeting, showing awareness of the temporal immanence of such experience in discussions - especially when, as he says, it is still 'raw' (quote 7), meaning recent, for the patients in the group. Chris explicitly acknowledges the conditioning role of biographical affect, yet at the same time he points tacitly to acceptable limits for emotional engagement within the deliberation process. Having already discussed the organization's decision to not re-appoint a patient that did not 'handle her emotions too well' (quote 5), we acquire a sense of just how narrow those acceptable limits of rational containment can be for patients. Yet as Maria's previously discussed example illustrated, patients also engage in rational containment: she decides that it might be "better for my own personal wellbeing" to join a more broadly-based cancer group that is less directly connected to her own biographical experience, "since it might have been a bit upsetting" to continue where she was (quote 2).

However, acceptable limits are also likely to affect professionals' own positioning in deliberation; for even if they are consciously imposed by their own narrative 
accounts, they are still to some extent responding to them emotionally. An example is this very different professional response from Stephen, another researcher:

Users certainly made us think. . . It may make us uncomfortable but it's very important nevertheless, I think it's very important to make bio-medical researchers uncomfortable, make them question what they do. . . So anything that brings the people's voice into that has got to be a good thing. From really senior people who maybe are not used to hearing a person's point of view like that, might find it a bit disturbing or a bit intrusive in their scientific train of thought in a meeting. There's nothing wrong with that (laughs) that's a good thing.

[Q8: Stephen, clinical researcher, interview, p.13]

Stephen seems here to eschew rational containment in favour of emotion's irrational challenge to the inherent rationality within involvement fora, because it is socially generative, or in his own words because 'users certainly made us think' (quote 8). We found Stephen's response particularly interesting in suggesting that being made to feel 'uncomfortable' when confronted with other participants' raw emotions might be rationally, as well as emotionally, generative - echoing the findings of Damasio (1994) that the rational is built out of the affective. Moreover, acknowledgement of affective structuring in this instance contributes to deliberation, making it acceptable for professionals to be 'affected' by its presence (Gottweis 2012). Although this study focuses primarily on non-professionals' emotions during deliberation, this insight would suggest that the biographical affect of professionals should form an equal focus for future studies. 
Other professionals also acknowledged biographical, affective structures as an important conditioning dimension, and positioned such acknowledgement as a stepping-stone for a more attentive approach to engaging with patients' lived experience within deliberations. Below is an excerpt from Robert's response:

I think for them it's almost a mission in life, and it's partly for them I guess trying to make sense or to, to redeem something from the tragedy that's happened, you know, the husband who died young or their daughter who died young, or whatever, and to use this experience in a way of shaping something else. Providing one acknowledges that, and also acknowledges their vulnerability that at times the issues under discussion may be hugely emotionally charged for them, I think they can be, they can be very helpful.

[Q9: Robert, clinical researcher interview, p. 7]

Emotional experience is here too welcomed in the organization, and appreciated for it's generative ability 'to shape something else' (quote 9). However in spite of welcoming such emotional charge of the deliberation process, Robert discursively positions it as something external to, rather than embedded in, deliberation, constituting a 'vulnerability’ (quote 9).

Hence implicit in all of these different organizational responses are tensions: most evidently, achievement of traditional organizational outcomes, such as maintaining consensus or appealing to clinical evidence, appeared to sit uneasily with emotional needs and identifications. For some, recalling Anderson (2013), it seems that 'some' 
emotion was necessary to preserve the professionalism of deliberation, by providing space for expressing safely what otherwise might have been seen as threatening, in its potential to jeopardize consensus around research funding. Endorsements for emotion's role in deliberation were partial, and seemed to passively acquiesce with affective structuring, whereby patient representatives were being emotionally present on the researchers' behalf (Anderson 2013). In this context, discomfort amongst participants was viewed as a positive deliberative outcome by the researchers, whilst underscoring the deep tension between these two dimensions, with emotionally charged views being seen as a 'disturbance' and 'intrusion' in the 'scientific train of thought', to use Stephen's (a researcher) words (quote 8), which ultimately seemed to legitimate rather than challenge existing norms governing deliberation.

\section{Discussion and conclusions}

The above observations make a significant contribution to studies of the operation of emotion, both within deliberation fora such as citizen participation in healthcare as well as within broader policy deliberation settings. We demonstrated that emotion can act as a medium through which participants' viscerally-experienced, past biographical experiences (or 'biographical affect') are able to condition the unfolding present - with institutional (organizational) consequences. The notion of biographical affect draws attention to the way in which participants may draw semi-consciously on temporally immanent affective structures that condition the emotional dimension of the deliberative process. In their ability to orient participants' future motivations and directedness, emotions constitute the medium through which (past) affective 
structures find expression, and agency, in the unfolding present. Finally, such affective structures, and emotional agency, are tempered as always by other, rationalist, institutional structures in a reciprocal relationship in which each modifies, and is modified, by the encounter.

Hence rather than simply asking how people might 'feel about' a given research question, design of a clinical trial, or intervention, we can begin to ask how biographical affect may consciously, semi-consciously, or unconsciously shape present actions and interpretations, as well as future expectations and projections that in turn affect clinical and organizational outcomes. For instance, Maria's case demonstrates that her unique biographical experience as palliative carer for a family member affects her self-positioning, and agency, within deliberation. In this way, emotionally-mediated affective structures impact on the obviously 'emotional', less consciously-mediated, minute-to-minute engagement within deliberation, such as emotional interruptions (see similar in Dryzek 2000 and Davies et al. 2006). However at the same time, our analysis showed that affective structures also colour otherwise apparently 'rational' decisions - such as deciding on the appropriate discussion in which to be involved, or where/how participants believe they will be able to contribute most effectively. Moreover, our analysis showed that emotion is potentially at play even in instances where we observed a rational/conscious privileging of the 'unemotional' over the 'emotional', indicated by researcher Chris' emotive endorsement of emotion before proposing its rational containment.

Additionally, Maria's case demonstrates that deliberation outcomes will depend to some degree on organizational responses to the operation of biographical affect. In 
this example, there is uncertainty over the possible response within the forum to Maria's conscious/unconscious self-positioning: will the organization 'slow down' offering room for the emotional intervention, but potentially allowing an unwelcome uneasiness to take over discussion - or will there be an attempt to re-focus on Maria's 'professional' positioning? Further, will the forum use the temporary suspension of deliberation rules to protect its own unfolding agenda? What is certain is that any agreement reached will be multi-faceted insofar as participants' interpretations and expectations about a decision will likely vary, according to their unique feelings about the outcome.

Regardless of eventual outcome, it is clear that the operation of biographical affective structures in the present is always equivocal, dependent on other elements as events unfold, and politically contested - with important implications for current theorizing of public deliberation within health settings and beyond. First, a focus on biographical affect addresses the prevailing dualism of emotion-versus-reason contained in much of the policy deliberation debate (Barnes 2008). Our study suggests, in particular, that questions of how actors reason (in an emotionally charged manner) and what they reason about (such as more attentive cancer care or more patient voice) are mutually constitutive and should thus be considered together. Acknowledgement of the 'what' as a political aim points to the inseparability of affect and reason even in less conscious (reactive) forms of affective structuring - for example, the patient's 'off putting' intervention discussed by manager Rita. This finding challenges the view that deliberation practitioners are less (or more) likely to define their aims in terms of what is 'rational' or 'reasonable' (Levine and Nierras 2007). 
On the other hand, as some of the organizational responses to affective structuring seek to incorporate patient involvement into existing goals, future research might attend to the potential of emotion to be used as a technique for 'rational deliberation by other means', in which emotional content of deliberation could be co-opted by managers (Parfitt 2004). This would deepen Dryzek's (2000) observation that emotion can be coercive (to be 'corrected' via deliberative democracy) into an investigation of ways in which emotion may be anticipated, deflected, harnessed, or otherwise 'turned' to support particular 'political rationalities' (Behagel and Arts 2014). In this sense, it may be useful to complement analyses of 'political rationalities' within deliberative democracy with a consideration of 'political emotionalities', and consider the degree of (mis)alignment and tension between the two dimensions.

We suggest that greater focus on political emotionalities might address Eriksson's (2012) critique of rational deliberation's reduction of participation to pre-defined agendas, and thus encompass alternative possibilities for pursuing the 'democratic promise' contained in deliberative fora. Such a view resonates with recent public policy scholarship arguing that critical reflections on the deliberative model are insufficient, unless they also 'explore the potential of . . . new framings of the policy process to generate new solutions, and to suggest how far actors . . . are able to enact new worlds within the confines of the present.' (Newman 2013, p. 515). Importantly, political emotionalities generating 'new framings' are able to accommodate 'more disorderly and decentered' communication (Young 2001), contributing to the idea of 'vibrant democracy' at the heart of Habermas's deliberative democracy. 
At the same time, exploration of such participatory possibilities (e.g. Font and Navarro 2013, in this journal) through affective structuring has relevance to other organizational contexts, beyond formal deliberative fora such as our case study. In theory, the principle that biographical affect operates both to constrain and enable unfolding social interaction applies universally, thus inviting consideration of ways in which predominant, rationalist discourses may provoke affectively-experienced tensions within other 'participation environments' - as well as analysis of the possible consequences of actors' attempts to negotiate such tensions in terms of altered outcomes. Potential settings include activist organizations such as direct action groups, health activist and other self-organized communities operating in the periphery - rather than within - public organizations. As a lens, biographical affect enables appreciation of how practices such as street demonstrations and sit-ins are both a response to as well as a manifestation of the tension between rational and affective problem-framing. In the current institutional shift from grassroots citizen engagement to more government-sponsored structures of participation, it seems more important than ever to understand the role of 'emotional reflexivity' (Brown and Pickerill 2009) in bottom-up, community-organized policy interventions.

Lastly, acknowledgement of the emotional, as well as rational, politics of deliberation invites the question of generalisability of our findings. Here we acknowledge the practical limitations of a research design founded on the centrality of the affective in structuring organizational practice, in the sense that we may have 'found what we were looking for'; a particularly tricky characteristic of studying emotion is that it is impossible to attribute causality in any definitive sense. 
Relatedly, it is important to recognize the range of influences, beyond emotion, on the deliberative process; emotion's role could be considered in conjunction with other key 'communicative functions' (Ocasio et al. 2015) through which institutional structures such as those of deliberative fora are recursively reproduced. There are also practical implications of such challenges for research into deliberation. In discussing "ways of knowing emotion", Sturdy (2003) argues that "immediate and biographical history...may provide insight into the emotional context and process" (pp. 86-7), where the researcher performs an interpretation of others' emotions based on their basic competence as a social operator. In turn, inclusion of more explicit emotional analysis may encourage techniques such as ethnography, personal recollection, diaries, interviews and storytelling (e.g. Averill 1980; Harre and Parrott 1996 in deliberation studies - with a particular emphasis on the reflexivity of the researcher, who is inevitably drawn into the study herself (Fineman 2004). The view presented here is that such techniques may encourage an increased 'emotional literacy' within deliberation discourse, enhancing deliberation's ability to discharge its core purpose of 'giving, weighing, acceptance or rejection of reasons' (Parkinson, op.cit.).

\section{Acknowledgments}

We would like to thank Marianna Fotaki and Alicia Renedo for reading and commenting on earlier drafts of the paper.

\section{Bibliography}


Abelson, J., P. Forest, J. Eyles, P. Smith, E. Martin, \& F. Gauvin. 2003. 'Deliberations about deliberative methods: issues in the design and evaluation of public participation processes'. Social science \& medicine, 57, 2, 239-251.

Alvesson M \& Sköldberg K. 2000. Reflexive methodology: New vistas for qualitative research, London: Sage.

Anderson, R. 2013. 'Doing Emotion, Doing Policy; the emotional role of "grassroots" community activists in poverty policy-making'. Chicago: Third Sector Research Centre Working Paper 96.

Anderson, R. 2014. 'Playing the fool: Activists' performances of emotion in policy making spaces'. Emotion, Space and Society, in press.

Archer, M. 2000. Being Human: The Problem of Agency. Cambridge: Cambridge University Press.

Averill, J.R. 1980. 'A constructivist view of emotion'. In R. Plutchik \& H. Kellerman (Eds), Theories of emotion. New York: Academic Press.

Baggott, R. 2005. 'A funny thing happened on the way to the forum? Reforming patient and public involvement in the NHS in England'. Public Administration, 83, 3, $533-551$.

Barber B. 1984. Strong Democracy. Berkeley: Univ. Calif. Press 
Barnes, M. 2008. 'Passionate participation: Emotional experiences and expressions in deliberative forums'. Critical social policy, 28, 4, 461-481.

Behagel, J. H., \& Arts, B. 2014. Democratic governance and political rationalities in the implementation of the water framework directive in the Netherlands. Public Administration, 92(2), 291-306.

Carpini, M. X. D., Cook, F. L., \& Jacobs, L. R. (2004). Public deliberation, discursive participation, and citizen engagement: A review of the empirical literature. Annu. Rev. Polit. Sci., 7, 315-344.

Dahl R. 1989. Democracy and Its Critics. New Haven, CT: Yale Univ. Press.

Carr, S. 2007. 'Participation, power, conflict and change: Theorizing dynamics of service user participation in the social care system of England and Wales'. Critical Social Policy, 27, 2, 266-276.

Davies, C., M. Wetherell, and E. Barnett. 2006. 'A Citizens Council in the making: dilemmas for citizens and their hosts'. Patients, the Public and Priorities in Healthcare, pp.129-138.

Department of Health. 2010. Equity and Excellence: Liberating the NHS. London: The Stationary Office.

Dewey J. 1954 (1927). The Public and Its Problems. Athens, OH: Swallow 2000. 
Dickinson, H., \& Sullivan, H. (2014). Towards a general theory of collaborative performance: The importance of efficacy and agency. Public Administration, 92(1), $161-177$.

Dryzek, J. 2000. Deliberative democracy and beyond: liberals, critics, contestations. Oxford: Oxford University Press.

Elfenbein, H. 2007 'Emotion in Organizations: A review in stages'. Institute for Research on Labor and Employment, UC Berkeley Working Paper 01-19-2007.

Elster J. 1998. Deliberative Democracy. Cambridge, UK: Cambridge Univ. Press

Emerson, R., R. Fretz, and L. Shaw. 2011. Writing ethnographic fieldnotes. University of Chicago Press.

Eriksson, K. 2012. 'Participative politics: self-service society'. Public Administration, $90,3,685-698$.

Fineman, S. 1993. Emotion in Organizations. Thousand Oaks, CA: Sage.

Fineman, S. 2004. 'Getting the measure of emotion - and the cautionary tale of emotional intelligence'. Human Relations 57: 719-740.

Fischer, F. 2010. 'Policy deliberation: confronting subjectivity and emotional expression'. Critical Policy Studies, i3, 3-4, 407-420. 
Fishkin J. 1995. The Voice of the People. New Haven, CT: Yale Univ. Press

Font, J., \& Navarro, C. 2013. Personal experience and the evaluation of participatory instruments in Spanish cities. Public Administration, 91(3), 616-631.

Fortier, A. M. (1999). 'Re-membering places and the performance of belonging(s)'. Theory, culture \& society, 16(2), 41-64.

Fotaki, M., K. Kenny, and S. Vachhani. 2014. 'Call for Papers: Thinking Critically about Affect in Organization Studies'. Special Issue for Organization: The Critical Journal of Organization, Theory and Society.

Froggatt, K., N. Preston, M. Turner, and C. Kerr. 2014. 'Patient and public involvement in research and the Cancer Experiences Collaborative: benefits and challenges'. BMJ supportive \& palliative care, bmjspcare-2013.

Gadamer, H. 1994. Truth and Method. New York: Continuum.

Goleman, D. 1998. Working with Emotional Intelligence. New York: Random House.

Gottwes, H. 2012. Stem Cell Policy in the United States. The Argumentative Turn Revisited: Public Policy as Communicative Practice, 211. 
Habermas J. 1975. The Legitimation Crisis of Late Capitalism translated by $\mathrm{T}$ McCarthy, Boston, MA: Beacon Press.

Habermas J. 1996. Between Facts and Norms: Contributions to a Discourse Theory of Law and Democracy. Trans. W. Rehg. Cambridge, MA: MIT Press.

Harré, R. \& Parrott, G.W. (Eds) 1996. The emotions: Social, cultural and biological dimensions. London: Sage.

Hendriks, C. 2002. 'Navigating the Murky Waters of Civil Society in Deliberative Democracy', paper read at Australasian Political Studies Association Conference, Canberra.

Herzberg, F. 1966. Work and the nature of man. Cleveland, OH. Holland.

Hochschild, A. 1983. The Managed Heart: Commercialization of Human Feeling. Berkeley: University of California Press.

Hochschild, A. 2011. 'Emotional life on the market frontier'. Annual Review of Sociology, 37, 21-33.

Hodge, S. 2005. Participation, discourse and power: a case study in service user involvement. Critical Social Policy, 25, 2, 164-179. 
Levine, P., \& Nierras, R. M. (2007). Activists' views of deliberation. Journal of public deliberation, $3(1), 4$.

Manning, N., and M. Holmes. 2014. 'Political Emotions: A Role for Feelings of Affinity in Citizens'(Dis) Engagements with Electoral Politics?'. Sociology, 48, 4, 698-714.

Marcus, G. 2002. The sentimental citizen: Emotion in democratic politics. Pennsylvania: Penn State University Press.

Martin, G. P. 2011. The third sector, user involvement and public service reform: a case study in the co-governance of health service provision. Public administration, 89(3), 909.

Martin, G. 2012. 'Public deliberation in action: Emotion, inclusion and exclusion in participatory decision making'. Critical Social Policy, 32, 2, 163-183.

Maslow, A. 1970. Motivation and Personality, 2nd. Ed., New York, Harper \& Row.

McLuhan, M., and Fiore, Q. 1967. The Medium Is the Massage, John Simon, producer. Conceived and co-ordinated by Jerome Agel. Columbia Stereo CS 9501, Mono CL 2701, ca. 1968. 
Montpetit, É. (2008). Policy design for legitimacy: Expert knowledge, citizens, time and inclusion in the United Kingdom's biotechnology sector. Public Administration, 86(1), 259-277.

Newman, J. 2013. Performing new worlds? Policy, politics and creative labour in hard times. Policy \& Politics, 41(4), 515-532.

Nussbaum, M. 2013. Political Emotions. Harvard University Press.

Ocasio, W., Loewenstein, J., \& Nigam, A. 2015. How Streams of Communication Reproduce and Change Institutional Logics: The Role of Categories. Academy of Management Review, 40(1), 28-48.

Parfitt, T. 2004. The ambiguity of participation: a qualified defence of participatory development. Third World Quarterly, 25, 3, 537-555.

Parkinson, J. (2004). Why deliberate? The encounter between deliberation and new public managers. Public administration, 82(2), 377-395.

Petit-Zeman, S., and L. Locock. 2013. 'Bring on the evidence'.' Nature, 501, 7466, $160-161$.

Renedo, A. and C. Marston, (2015). 'Creating spaces for effective public involvement in healthcare: an ethnographic study'. Sociology. 
Renedo, A., C. Marston, D, Spyridonidis, and J. Barlow. 2014. 'Patient and Public Involvement in Healthcare Quality Improvement: How organizations can help patients and professionals to collaborate'. Public Management Review, (ahead-ofprint), 1-18.

Schmidt, D., and D. Gibson. 2010. 'Emotions in Ethics and the Workplace: How can Feelings Be Integrated into Business Pedagogy?' $13^{\text {th }}$ Annual Colleagues in Jesuit Business Education (CJBE) Conference, Marquette University, Milwaukee, Wisconsin.

Serapioni, M., A. Matos (In Press). 'Citizen participation and discontent in three Southern European health systems'. Social Science \& Medicine.

Strauss, A. 1987. Qualitative Analysis for Social Scientists. Cambridge: Cambridge University Press.

Sturdy, A. 2003. Knowing the unknowable? A discussion of methodological and theoretical issues in emotion research and organization studies. Organization 10: 81105.

Sullivan, H. 2015, in Alexander, D., \& Lewis, J. M. (2014). Making public policy decisions. Making Public Policy Decisions: Expertise, Skills and Experience, 1.

Thien, D. 2005. 'After or beyond feeling? A consideration of affect and emotion in geography'. Area, 37, 4, 450-454. 
Thrift, N. 2004. 'Intensities of Feeling: Towards a Spatial Politics of Affect'. Geografiska Annaler 86,1, 57-58..

Thompson, M. 2012. 'People, practice, and technology: restoring Giddens' broader philosophy to the study of information systems'. Information and Organization, 22, 3, $188-207$.

Van Maanen, J., and G. Kunda. 1989. 'Real feelings - emotional expression and organizational culture'. Research in Organizational Behavior 11, 43-103.

Whitehead, M., Jones, R., \& Pykett, J. (2005). Governing irrationality, or a more than rational government? Reflections on the rescientisation of decision making in British public policy. Environment and Planning-Part A, 43(12), 2819.

Young, I. M. (2001). Activist challenges to deliberative democracy. Political theory, 670-690. 
Appendix: Table 1

\begin{tabular}{|l|l|l|}
\hline $\begin{array}{l}\text { Organizational } \\
\text { outcome }\end{array}$ & $\begin{array}{l}\text { Mode of affective } \\
\text { structuring }\end{array}$ & Respondent \\
\hline $\begin{array}{l}\text { Support } \\
\text { deliberation }\end{array}$ & $\begin{array}{l}\text { Proactive } \\
\text { emotional narrative } \\
\text { (more conscious) }\end{array}$ & $\begin{array}{l}\text { Maria (1) } \\
\text { Mike }\end{array}$ \\
\hline $\begin{array}{l}\text { Deviate } \\
\text { from/challenge } \\
\text { deliberation }\end{array}$ & $\begin{array}{l}\text { Reactive emotional } \\
\text { response }\end{array}$ & Maria (3) \\
\hline & $\begin{array}{l}\text { Reactive emotional narrative } \\
\text { response }\end{array}$ & Rita \\
\hline Organizational response
\end{tabular}

Table 1: Modes of affective structuring and organizational outcomes 